\title{
Could remifentanil reduce duration of mechanical ventilation in comparison with other opioids for mechanically ventilated patients? A systematic review and meta- analysis
}

Yibing Zhu ${ }^{1+} \mathbb{D}$, Yinhua Wang ${ }^{1,3+}$, Bin Du ${ }^{2^{*}}$ and Xiuming $\mathrm{Xi}^{1^{*}}$

\begin{abstract}
Background: Sedation and analgesia are commonly required to relieve anxiety and pain in mechanically ventilated patients. Fentanyl and morphine are the most frequently used opioids. Remifentanil is a selective $\mu$-opioid receptor that is metabolized by unspecific esterases and eliminated independently of liver or renal function. Remifentanil has a rapid onset and offset and a short context-sensitive half-life regardless of the duration of infusion, which may lead to reductions in weaning and extubation. We aimed to compare the efficacy and safety of remifentanil to that of other opioids in mechanically ventilated patients.

Methods: We conducted a search to identify relevant randomized controlled studies (RCTs) in the PubMed, Embase, Cochrane Library and SinoMed databases that had been published up to 31 December 2016. The results were analysed using weighted mean differences (WMDs) and 95\% confidence intervals (Cls).

Results: Twenty-three RCTs with 1905 patients were included. Remifentanil was associated with reductions in the duration of mechanical ventilation (mean difference $-1.46 ; 95 \% \mathrm{Cl}-2.44$ to -0.49 ), time to extubation after sedation cessation (mean difference $-1.02 ; 95 \% \mathrm{Cl}-1.59$ to -0.46 ), and ICU-LOS (mean difference $-0.10 ; 95 \% \mathrm{Cl}-0.16$ to -0.03 ). No significant differences were identified in hospital-LOS (mean difference $-0.05 ; 95 \% \mathrm{Cl}-0.25$ to 0.15 ), costs (mean difference $-709.71 ; 95 \% \mathrm{Cl}-1590.98$ to $171.55 ; \mathrm{I}^{2} 88 \%$ ), mortality (mean difference $-0.64 ; 95 \% \mathrm{Cl}-1.33$ to $0.06 ; \mathrm{I}^{2} 87 \%$ ) or agitation (mean difference $-0.71 ; 95 \% \mathrm{Cl}-1.80$ to $0.37 ; 1^{2} 93 \%$ ).

Conclusions: Remifentanil seems to be associated with reductions in the duration of mechanical ventilation, time to extubation after cessation of sedation, and ICU-LOS. No significant differences were identified between remifentanil and other opioids in terms of hospital-LOS, costs, mortality or agitation.
\end{abstract}

Keywords: Analgesia, Remifentanil, Mechanical ventilation, Meta-analysis, Systematic review, Critical care

\footnotetext{
* Correspondence: dubin98@gmail.com; xixiuming2937@sina.com

${ }^{\dagger}$ Equal contributors

${ }^{2}$ Medical ICU, Peking Union Medical College Hospital, Peking Union Medical College and Chinese Academy of Medical Sciences, 1 Shuai Fu Yuan, Beijing 100730, China

'Department of Critical Care Medicine, Fuxing Hospital, Capital Medical University, 20A FuXing Men Wai Da Jie, Xicheng District, Beijing 100038, China

Full list of author information is available at the end of the article
} 


\section{Background}

Pain and anxiety are among the worst experiences for the critically ill, especially those on mechanical ventilation. Mechanically ventilated patients generally require a combination of analgesia and sedation to improve compliance with mechanical ventilation, adaption to endotracheal tubes, and pain relief [1]. Propofol and midazolam have been identified as the hypnotic drugs most commonly used for sedation in the intensive care unit (ICU), and among sedatives, shorter elimination halflives are associated with shorter awakening times, resulting in reductions in time to weaning and time to extubation [2]. Opioids are commonly used in the ICU for analgesia, and the accumulation of opioid agents may cause respiratory depression, thus leading to prolongation of time to weaning and extubation.

Studies have found the most frequently used opioids to be fentanyl (30-35\%), morphine (15-33\%), and sufentanil (25-40\%), the specific proportions of which differ in the results of different surveys, with remifentanil being less commonly used $(10 \%)[3,4]$. However, the use of opioids may not be ideal in mechanically ventilated critically ill patients. The renal metabolism of morphine results in accumulation of morphine-6-glucuronide in patients with renal impairment. In addition, common adverse effects of morphine include histamine release, pruritus, and constipation [5]. Fentanyl, alfentanil and sufentanil undergo hepatic metabolism, and continuous infusion results in accumulation and prolongation of effect [5]. Those pharmacodynamic and pharmacokinetic profiles have disadvantages in terms of rapid weaning and extubation.

Similar to fentanyl, alfentanil, and sufentanil, remifentanil is a potent, selective 4 -anilidopiperidine $\mu$-opioid analgesic. However, unlike fentanyl and other opioids, remifentanil is completely metabolized by unspecific esterases in a manner that is independent of liver or renal function $[5,6]$. Since unspecific esterases have been found to be widely distributed in living human cells, there are no ICU disease states or types of organ failure that would lead to reduced breakdown of remifentanil. The major breakdown product of remifentanil is remifentanil acid (RA), which has a potency of only $1 / 300$ to $1 / 4600$ that of remifentanil, has poor brain penetration and is unlikely to cause respiratory failure $[6,7]$. Remifentanil has a highly predictable onset and offset effect, a terminal half-life of approximately 10 to 20 minutes, and a context-sensitive half-life of 3 to 4 minutes $[6,8]$. The unique pharmacokinetics of remifentanil may lead to reductions in time to weaning and extubation and, accordingly, may be associated with reductions in mechanical ventilation time, length of ICU stay (ICU-LOS), and costs.

Several randomized controlled studies (RCTs) and cohort studies have been conducted to compare the efficacy and safety of remifentanil with those of other opioids. Mechanical ventilation time and extubation time are commonly evaluated indicators. Taking Dahaba et al.'s study [1] as an example, 40 mechanically ventilated patients who were assigned an analgesia protocol involving the administration of either remifentanil or morphine; these analgesics were initiated at the minimum dose and titrated up to an optimal level of sedation, with midazolam serving as a rescue treatment. The results of this study showed that remifentanil was associated with significant reductions in mean duration of mechanical ventilation and extubation time. The same outcome measures have been assessed in several RCTs). The results of a meta-analysis [9] showed that remifentanil was associated with reduced time to extubation after sedation cessation, but no significant difference was identified between remifentanil and other opioids in terms of mechanical ventilation duration. However, another meta-analysis [10] showed that remifentanil was associated with a significantly reduction in the duration of mechanical ventilation. The results of a costconsequence analysis performed by $\mathrm{Al}$ et al. [11] suggested that remifentanil was associated with significantly decreased ICU costs, whereas the results of Engoren et al.'s study [12] showed that higher opioid and anaesthetic costs but lower hospital costs were identified in remifentanil group relative to the fentanyl group. The results of these economic analyses were complex. On the one hand, reductions in ventilation time, ICU-LOS and length of stay in hospital (hospital-LOS) were associated with a reduction in overall cost, but shorter-acting anaesthetics were more expensive. On the other hand, morphine withdrawal-associated immunosuppression and remifentanil discontinuation were identified as independent risk factors for ICU-acquired infections, and excessive analgesia was associated with nosocomial pneumonia delirium and psychological disorders, which increases the complexity of the evaluation of remifentanil [13]. Several studies have been conducted since the meta-analysis was performed in 2009 [10], which showed that remifentanil was associated with reduced time to extubation after sedation cessation and indicated the presence of no significant differences between remifentanil and other opioids in terms of mortality, duration of mechanical ventilation, ICU-LOS, and risk of agitation. Therefore, we conducted this study with the intention of updating these data and re-evaluating the efficacy and safety of remifentanil in mechanically ventilated patients relative to the safety and efficacy of other opioids.

\section{Methods}

Search strategy and selection criteria

Four electronic databases were searched (PubMed, Embase, Cochrane Library and SinoMed)) to identify 
studies published from 2001 until December 2016. A search strategy was developed for PubMed (Additional file 1: Appendix 1) and the other databases. Our research was limited to RCTs, and no language restriction was applied. The reference lists of relevant articles were also reviewed. We contacted the authors of the studies if additional data were required for the predefined outcomes. Non-English language articles were translated before further analysis.

Studies were included if they met the following criteria: (1) the study population consisted of adults (mean age $\geq 18$ years old) undergoing mechanical ventilation; (2) the study design was an RCT; (3) remifentanil or a remifentanil/sedative combination was used for analgesia and sedation; and (4) the outcomes included at least one of the following measures: duration of mechanical ventilation, time to extubation after cessation of sedation, ICU-LOS, hospital-LOS, costs, proportion of patients with agitation, delirium, nausea/vomiting, or mortality.

Studies in which remifentanil was not compared with another opioid or another opioid/sedative combination were excluded. Publications available only in abstract form or as meeting reports were excluded.

\section{Data extraction and quality assessment}

Two reviewers (ZYB and WYH) independently extracted data from the published sources using a predesigned data extraction form. The following data were abstracted from each included study: the study ID, journal, year of publication, country, setting, centre, mean age, proportion of male subjects, disease severity, disease type, proportion of post-surgical patients, sample size, comparator, inclusion criteria, exclusion criteria, intervention and outcomes. Two reviewers independently rated the quality of the RCTs using the Modified Jadad scores [14], which are determined using a checklist designed to measure the quality of RCT reporting. The following elements are evaluated when calculating a Modified Jadad score: randomization (0-2), concealment of allocation $(0-2)$, double blinding (0-2), and withdrawals and dropouts $(0-1)$. The trials were rated based on what they reported, and the results of the quality assessment are described in the table describing the characteristics of included studies (Table 1).

Discordant opinions between the two reviewers were discussed until consensus was reached. If consensus could not be reached, a consulting group including two experts (XXM and DB) resolved the disagreements.

\section{Outcomes and statistical analysis}

The primary outcome was duration of mechanical ventilation. The primary outcome was analysed in five subgroups: analgesia only; analgesia and sedation; and comparisons of remifentanil with fentanyl, morphine, and/or sufentanil. The secondary outcomes included (1) time to extubation after cessation of sedation; (2) ICULOS; (3) hospital-LOS; (4) costs; (5) mortality; and (6) agitation. Costs were measured in dollars, and other currencies converted into dollars according to the 2016 exchange rate. The costs were measured as overall costs, such as ICU or hospital costs. Maximum costs were preferentially used if a study reported more than one cost measure.

The pooled effects were analysed using weighted mean differences (WMDs) and 95\% confidence intervals (CIs). The presence of statistically significant heterogeneity across trials was quantitatively assessed using the $\mathrm{I}^{2}$ statistic. Inverse variance random-effects models were applied for the data analysis. Publication bias was evaluated using funnel plots when at least ten studies were included in this meta-analysis. A $p$ value less than 0.05 was considered statistically significant. All statistical analyses were performed using Review Manager Version 5.3.

\section{Results \\ Study selection}

Overall, 585 potentially relevant articles were identified using the search strategy. After screening the titles/abstracts of the studies, 49 articles remained and were obtained in full-text form. Twenty-six studies failed to meet the previously described inclusion criteria; therefore, 23 studies were included in this meta-analysis. Of the included studies, 19 were published in English, two were published in French, one was published in Chinese, and one was published in Thai. No relevant unpublished studies were identified. Figure 1 presents the study selection process.

\section{Study characteristics and quality}

A total of 1905 critically ill adult patients were included in the studies subjected to meta-analysis. The sample sizes of the 23 included studies ranged from 20 to 205 participants. Twenty-two studies compared remifentanil with another one or two opioids, and one study compared remifentanil/propofol with fentanyl/midazolam. Table 1 summarizes the basic characteristics of the included studies.

The results of the study quality assessment showed that five of the 23 RCTs were of high quality (Modified Jadad score 4-7), and the other 18 RCTs were of suboptimal quality (Modified Jadad score $0-4$ ); these studies commonly lacked details regarding concealment of allocation and withdrawals and dropouts. Table 2 summarizes the quality of the included RCTs.

\section{Outcomes}

The primary outcome, duration of mechanical ventilation, was reported in 18 RCTs. Remifentanil was 


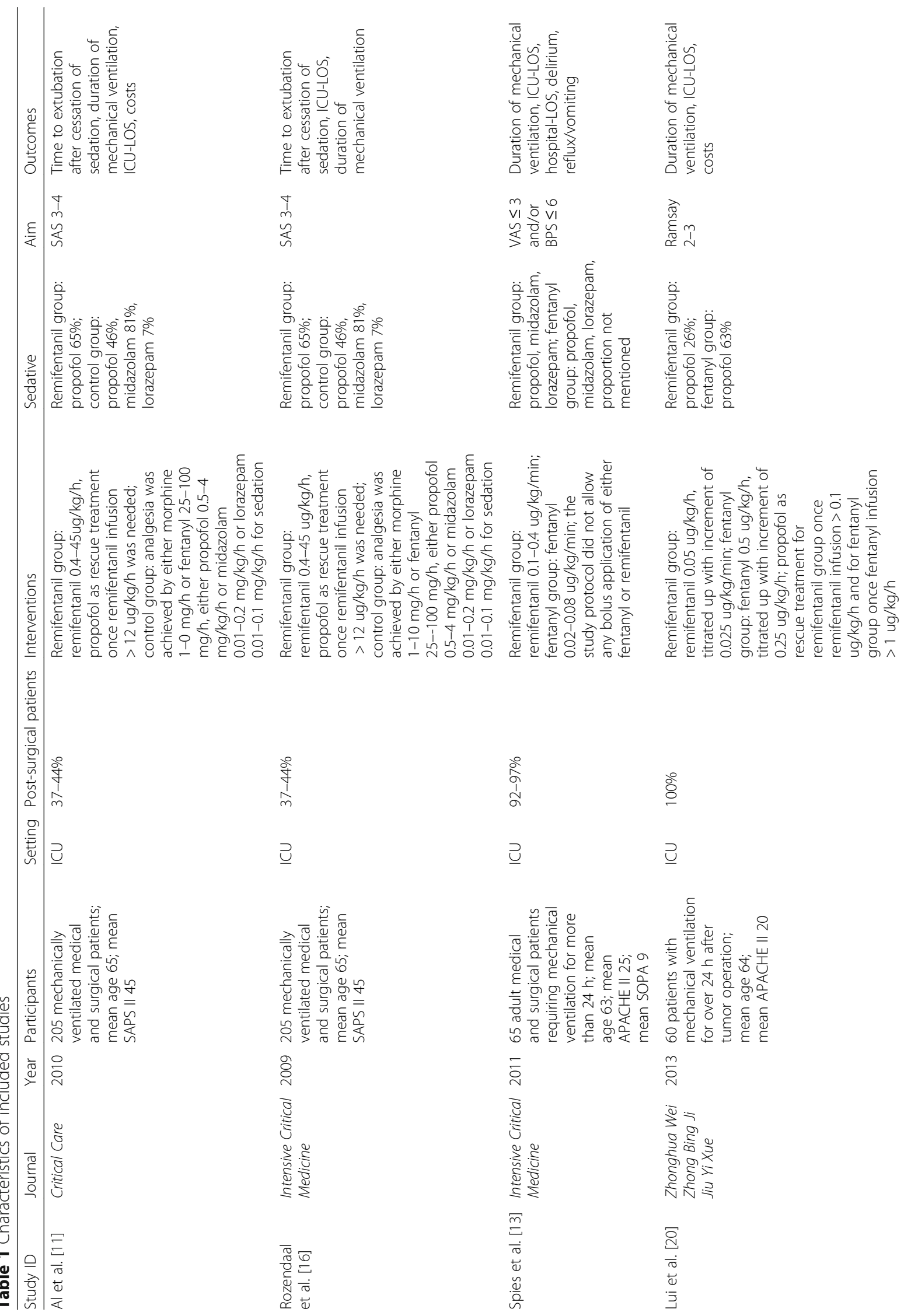




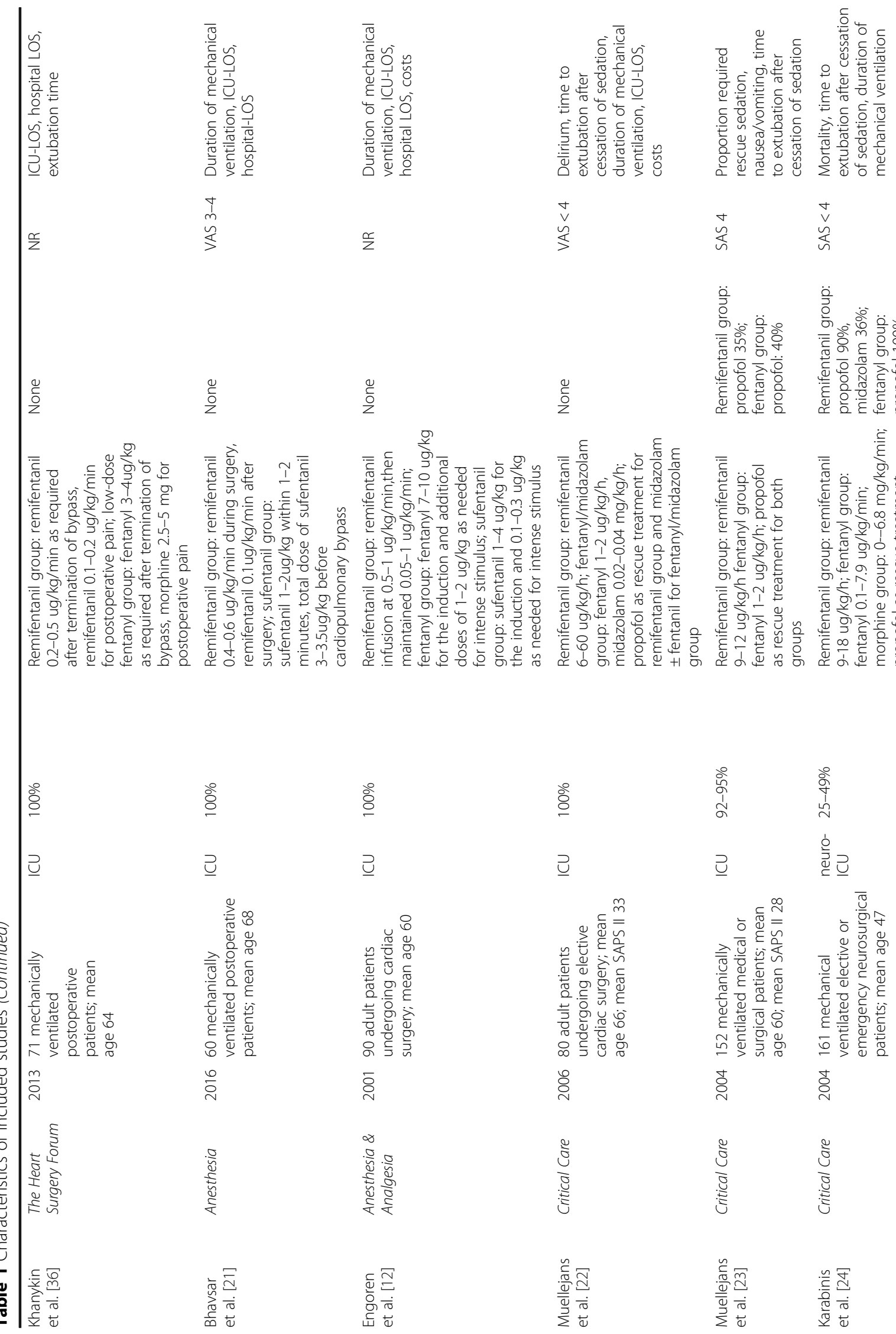




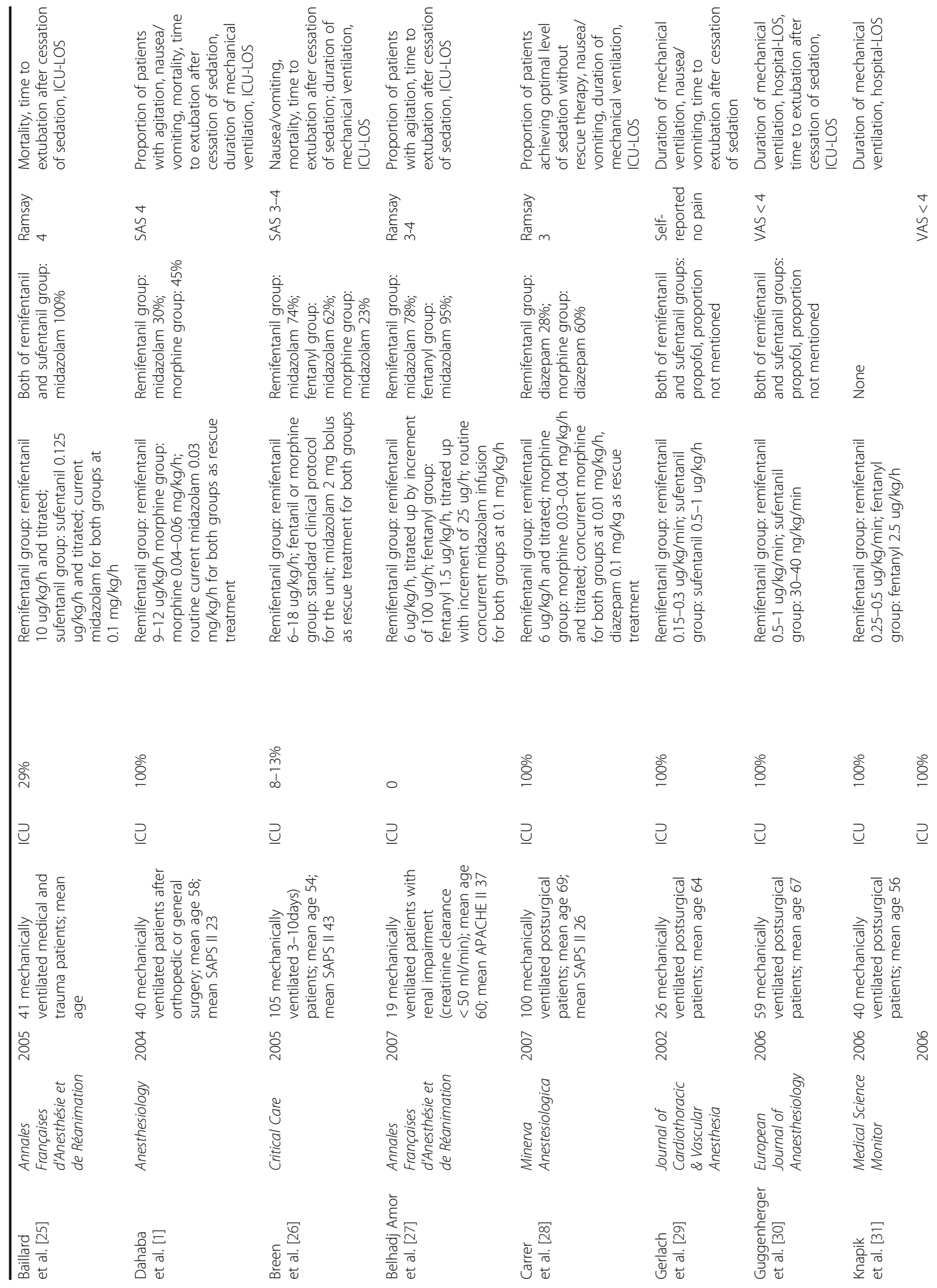




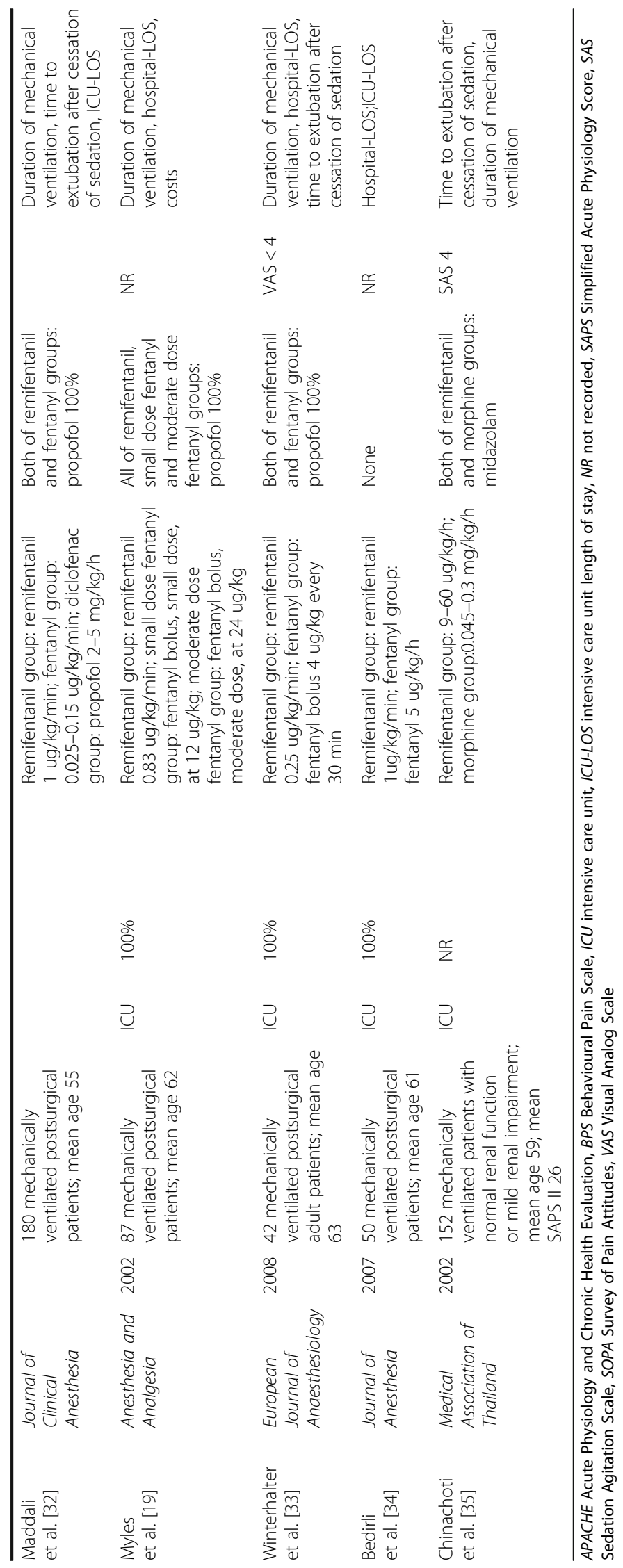




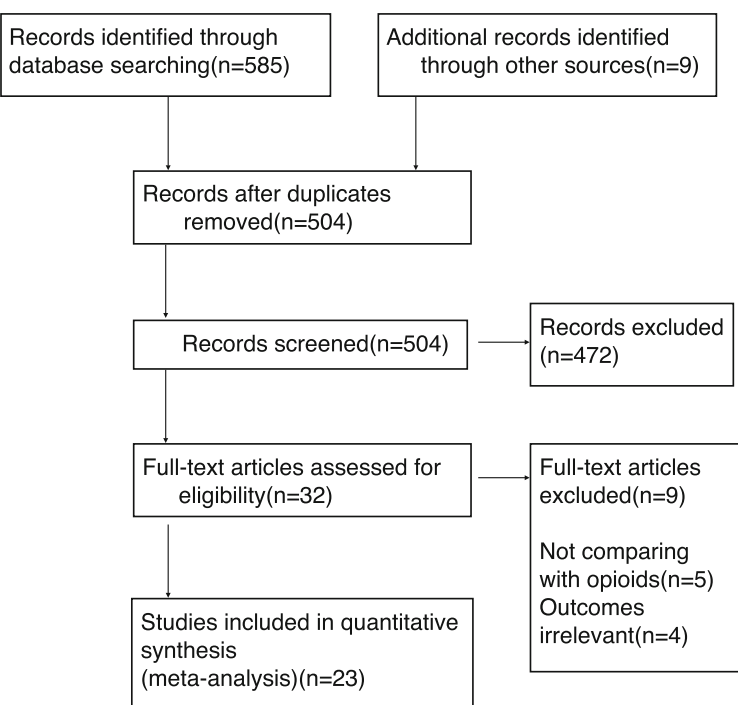

Fig. 1 Flow diagram of the process for identification of the included studies associated with a reduction in the duration of mechanical ventilation (mean difference -1.46; 95\% CI -2.44 to $-0.49 ; \mathrm{I}^{2} 89 \%$. Fig. 2a).

As for the secondary outcomes, remifentanil was associated with reductions in time to extubation after sedation cessation (mean difference -1.02; 95\% CI -1.59 to $-0.46 ; \mathrm{I}^{2} 96 \%$. Fig. 3a) and ICU-LOS (mean difference -0.10 ; $95 \%$ CI -0.16 to $-0.03 ; \mathrm{I}^{2} 85 \%$. Fig. $3 \mathrm{~b}$ ). No significant differences in hospital-LOS (mean difference $-0.05 ; 95 \%$ CI -0.25 to $0.15 ; \mathrm{I}^{2} 88 \%$. Additional file 2: Figure S2a), costs (mean difference $-709.71 ; 95 \%$ CI -1590.98 to $171.55 ; \mathrm{I}^{2} 88 \%$. Additional file 2: Figure S2b), mortality (mean difference $-0.64 ; 95 \%$ CI -1.33 to $0.06 ; \mathrm{I}^{2}$ $87 \%$. Additional file 2: Figure S2c) and agitation (mean difference $-0.71 ; 95 \%$ CI -1.80 to $0.37 ; \mathrm{I}^{2}$ 93\%. Additional file 2: Figure S2d) were identified. Table 3 summarizes the data for and analyses of outcome measures.

As for the subgroup analyses, remifentanil was associated with a reduction in mechanical ventilation duration in the subgroup of studies in which both analgesia and sedation were administered (mean difference -2.99; 95\% CI -5.09 to $-0.89 ; \mathrm{I}^{2} 84 \%$. Additional file 3: Figure S1a) and the subgroup of studies in which remifentanil

Table 2 Quality assessment of included RCTs

\begin{tabular}{|c|c|c|c|c|c|c|}
\hline Study ID & Randomization & $\begin{array}{l}\text { Concealment of } \\
\text { allocation }\end{array}$ & $\begin{array}{l}\text { Double } \\
\text { blinding }\end{array}$ & $\begin{array}{l}\text { Withdraws and } \\
\text { dropouts }\end{array}$ & $\begin{array}{l}\text { Modified Jadad } \\
\text { score }\end{array}$ & $\begin{array}{l}\text { Quality } \\
\text { assessment }\end{array}$ \\
\hline Al et al. [11] & 2 & 0 & 0 & 0 & 2 & Low \\
\hline Rozendaal et al. [16] & 2 & 0 & 0 & 0 & 2 & Low \\
\hline Spies et al. [13] & 2 & 2 & 2 & 1 & 7 & High \\
\hline Liu et al. [20] & 2 & 0 & 0 & 0 & 2 & Low \\
\hline Khanykin et al. [36] & 2 & 0 & 0 & 1 & 3 & Low \\
\hline Bhavsar et al. [21] & 2 & 0 & 0 & 0 & 2 & Low \\
\hline Engoren et al. [12] & 2 & 0 & 0 & 0 & 2 & Low \\
\hline Muellejans et al. [22] & 1 & 0 & 0 & 1 & 2 & Low \\
\hline Muellejans et al. [23] & 1 & 0 & 1 & 1 & 3 & Low \\
\hline Karabinis et al. [24] & 1 & 0 & 0 & 0 & 1 & Low \\
\hline Baillard et al. [25] & 2 & 0 & 1 & 0 & 3 & Low \\
\hline Dahaba et al. [1] & 2 & 2 & 2 & 1 & 7 & High \\
\hline Breen et al. [26] & 1 & 0 & 0 & 0 & 1 & Low \\
\hline Belhadj Amor et al. [27] & 2 & 0 & 2 & 0 & 4 & Low \\
\hline Carrer et al. [28] & 1 & 0 & 0 & 0 & 1 & Low \\
\hline Gerlach et al. [29] & 2 & 2 & 0 & 0 & 4 & High \\
\hline Guggenherger et al. [30] & 2 & 0 & 0 & 1 & 3 & Low \\
\hline Knapik et al. [31] & 1 & 0 & 0 & 0 & 1 & Low \\
\hline Maddali et al. [32] & 2 & 0 & 0 & 1 & 3 & Low \\
\hline Myles et al. [19] & 2 & 0 & 2 & 1 & 5 & High \\
\hline Winterhalter et al. [33] & 2 & 2 & 2 & 0 & 6 & High \\
\hline Bedirli et al. [34] & 2 & 0 & 0 & 0 & 2 & Low \\
\hline Chinachoti et al. [35] & 2 & 0 & 1 & 0 & 3 & Low \\
\hline
\end{tabular}




\begin{tabular}{|c|c|c|c|c|c|c|c|c|c|c|}
\hline \multirow[b]{2}{*}{ Study or Subgroup } & \multicolumn{3}{|c|}{ remifentanil } & \multicolumn{3}{|c|}{ other opioid } & \multirow[b]{2}{*}{ Weight } & \multirow{2}{*}{$\begin{array}{l}\text { Mean Difference } \\
\text { IV, Random, } 95 \% \mathrm{CI}\end{array}$} & \multirow{2}{*}{\multicolumn{2}{|c|}{$\begin{array}{c}\text { Mean Difference } \\
\text { IV, Random, } 95 \% \mathrm{CI}\end{array}$}} \\
\hline & Mean & SD & Total & Mean & SD & Total & & & & \\
\hline Breen 2005 & 94 & 13.9 & 57 & 147.6 & 159.1 & 48 & $0.0 \%$ & $-53.60[-98.75,-8.45]$ & & \\
\hline Carrer 2007 & 17 & 6 & 50 & 18 & 4 & 50 & $6.8 \%$ & $-1.00[-3.00,1.00]$ & & \\
\hline Chinachoti 2002 & 15.7 & 9.7 & 74 & 14.4 & 7.5 & 78 & $5.4 \%$ & $1.30[-1.47,4.07]$ & & \\
\hline Claudia 2011 & 136 & 28.5 & 28 & 162 & 33.6 & 32 & $0.4 \%$ & $-26.00[-41.72,-10.28]$ & & \\
\hline Dahaba 2004 & 14.1 & 2.8 & 20 & 18 & 3.3 & 20 & $7.0 \%$ & $-3.90[-5.80,-2.00]$ & $\rightarrow$ & \\
\hline Gerlach 2002 & 4.7 & 5.3 & 13 & 7.5 & 4.3 & 13 & $4.0 \%$ & $-2.80[-6.51,0.91]$ & & \\
\hline Guggenherger 2006 & 5.4 & 1.7 & 25 & 6.2 & 2.3 & 25 & $8.5 \%$ & $-0.80[-1.92,0.32]$ & & \\
\hline Karabinis 2004 & 46.8 & 29 & 84 & 40.7 & 34.1 & 40 & $0.6 \%$ & $6.10[-6.15,18.35]$ & & \\
\hline Karabinis 2004 & 46.8 & 29 & 84 & 35.2 & 29.5 & 37 & $0.7 \%$ & $11.60[0.25,22.95]$ & & \\
\hline Knapik 2006 & 4.2 & 4.7 & 20 & 5.7 & 3.9 & 20 & $5.6 \%$ & $-1.50[-4.18,1.18]$ & & \\
\hline Maddali 2006 & 10.7 & 4.5 & 58 & 10.8 & 5.8 & 59 & $7.0 \%$ & $-0.10[-1.98,1.78]$ & & \\
\hline Milo 2001 & 3.9 & 1.07 & 29 & 2.78 & 1.21 & 33 & $9.2 \%$ & $1.12[0.55,1.69]$ & & - \\
\hline Milo 2001 & 3.9 & 1.07 & 29 & 4.75 & 0.68 & 28 & $9.3 \%$ & $-0.85[-1.31,-0.39]$ & & \\
\hline Muellejans 2004 & 20.6 & 5.2 & 40 & 24.2 & 6.9 & 39 & $5.5 \%$ & $-3.60[-6.30,-0.90]$ & $\rightarrow$ & \\
\hline Muellejans 2006 & 18.5 & 2.5 & 39 & 18.5 & 2.2 & 33 & $8.5 \%$ & $0.00[-1.09,1.09]$ & & \\
\hline Myles 2002 & 9.4 & 5.7 & 29 & 20.9 & 9.1 & 55 & $4.8 \%$ & $-11.50[-14.68,-8.32]$ & 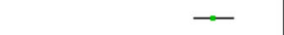 & \\
\hline Rajesh 2016 & 5.18 & 0.53 & 30 & 4.35 & 0.66 & 30 & $9.4 \%$ & $0.83[0.53,1.13]$ & & \\
\hline Rozendaal 2009 & 93.6 & 312.7 & 96 & 122.4 & 410.8 & 109 & $0.0 \%$ & $-28.80[-128.10,70.50]$ & & \\
\hline Wang 2013 & 73.6 & 26.7 & 30 & 94.9 & 37.3 & 30 & $0.3 \%$ & $-21.30[-37.71,-4.89]$ & & \\
\hline Winterhalter 2008 & 4 & 3 & 20 & 6.9 & 3.5 & 21 & $6.8 \%$ & $-2.90[-4.89,-0.91]$ & - & \\
\hline Total $(95 \% \mathrm{Cl})$ & & & 855 & & & 800 & $100.0 \%$ & $-1.46[-2.44,-0.49]$ & & - \\
\hline \multicolumn{9}{|c|}{$\begin{array}{l}\text { Heterogeneity. } \text { Tau }^{2}=2.62 ; \mathrm{Chi}^{2}=170.50, \mathrm{df}=19(\mathrm{P}<0.00001) ;\left.\right|^{2}=89 \% \\
\text { Test for overall effect: } \mathrm{Z}=2.93(\mathrm{P}=0.003)\end{array}$} & $\begin{array}{cc}-\frac{1}{2} 0 & -10 \\
\text { Favours [experimental] }\end{array}$ & $\frac{1}{10} \frac{1}{20}$ \\
\hline
\end{tabular}

Fig. 2 Primary outcome. Remifentanil was associated with a reduction in duration of mechanical ventilation

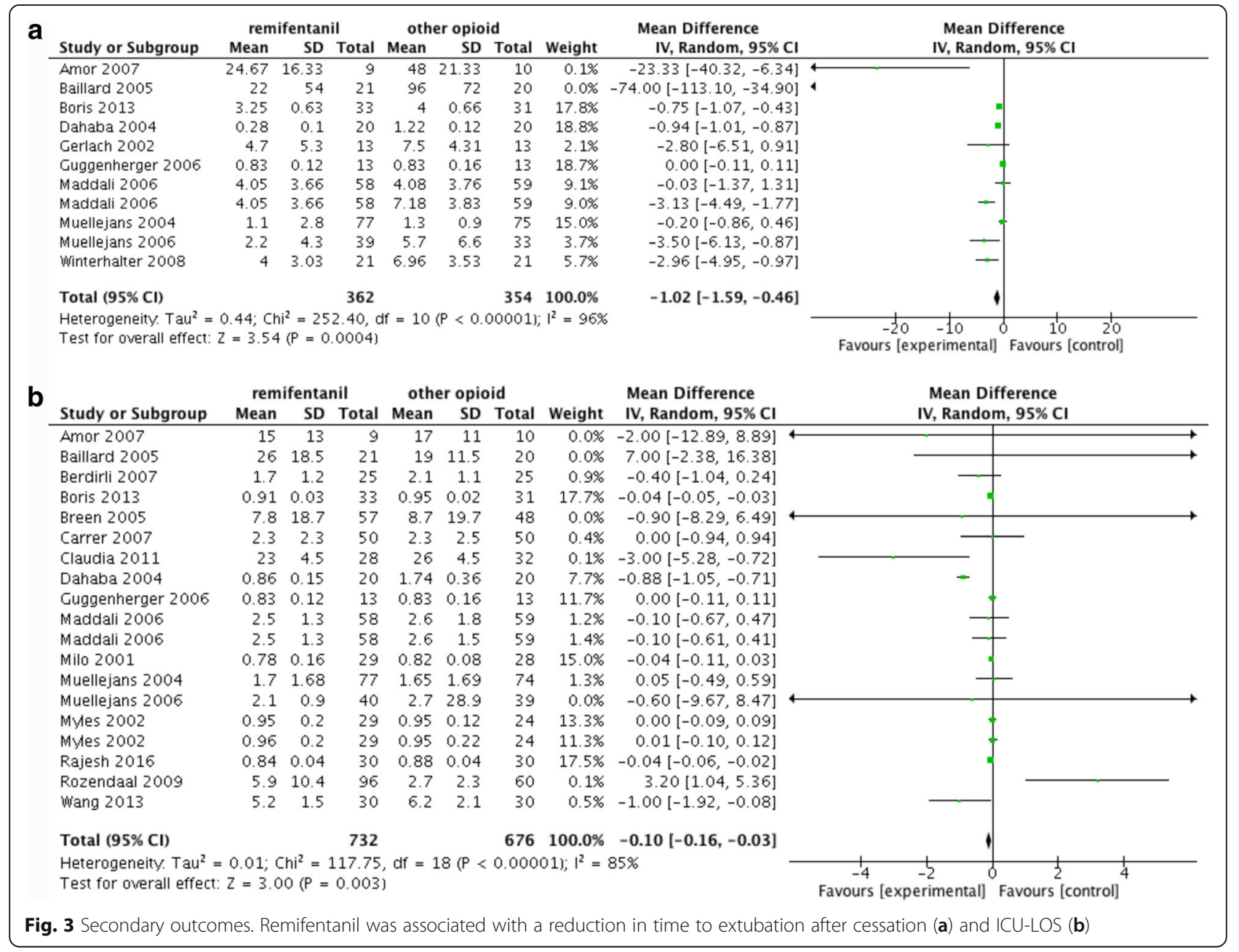


Table 3 Data and analyses of outcome measures

\begin{tabular}{|c|c|c|c|c|c|}
\hline Outcome & Studies & Participants & Effect estimate & Heterogeneity $\left(1^{2}\right)$ & Measure \\
\hline Duration of mechanical ventilation (Fig. 1) & 18 & 1655 & $-1.46[-2.44]$ & $89 \%$ & Hour \\
\hline Subgroup of analgesia only (Additional file 3: Figure S1a) & 4 & 291 & $0.14[-0.79]$ & $91 \%$ & Hour \\
\hline Subgroup of analgesia and sedation (Additional file 3: Figure S1b) & 14 & 1364 & $-2.99[-5.09]$ & $84 \%$ & Hour \\
\hline $\begin{array}{l}\text { Subgroup of remifentanil comparing with fentanyl } \\
\text { (Additional file 3: Figure S1c) }\end{array}$ & 8 & 624 & $-3.85[-7.39]$ & $93 \%$ & Hour \\
\hline $\begin{array}{l}\text { Subgroup of remifentanil comparing with morphine } \\
\text { (Additional file 3: Figure S1d) }\end{array}$ & 4 & 416 & $-0.98[-3.81]$ & $74 \%$ & Hour \\
\hline $\begin{array}{l}\text { Subgroup of remifentanil comparing with remifentanil } \\
\text { (Additional file 3: Figure S1e) }\end{array}$ & 5 & 233 & $-0.58[-1.78]$ & $91 \%$ & Hour \\
\hline Time to extubation after cessation of sedation (Fig. 2) & 10 & 716 & $-0.68[-0.74]$ & $96 \%$ & Hour \\
\hline ICU-LOS (Fig. 2) & 17 & 1408 & $-0.04[-0.05]$ & $85 \%$ & Day \\
\hline Hospital-LOS (Additional file 2: Figure S2a) & 9 & 507 & $-0.05[-0.25]$ & $88 \%$ & Day \\
\hline Costs (Additional file 2: Figure S2b) & 4 & 437 & $943.54[-1122.69]$ & $90 \%$ & Dollar \\
\hline Mortality (Additional file 2: Fig. S2c) & 10 & 260 & $-0.64[-1.33]$ & $87 \%$ & Person \\
\hline Agitation (Additional file 2: Fig S2d) & 3 & 184 & $-0.71[-1.80]$ & $93 \%$ & Person \\
\hline Delirium (Additional file 2: Figure S2e) & 4 & 323 & $1.01[0.63]$ & 0 & Person \\
\hline
\end{tabular}

and fentanyl were compared (mean difference -3.85; 95\% CI -7.39 to $-0.31 ; \mathrm{I}^{2} 93 \%$. Additional file 3: Figure S1c). No significant differences were identified in the subgroup of studies in which only analgesia was administered (mean difference $0.14 ; 95 \%$ CI -0.79 to $1.07 ; \mathrm{I}^{2}$ $91 \%$. Additional file 3: Figure S1a), the subgroup of studies in which remifentanil and morphine were compared (mean difference -0.98 ; 95\% CI -3.81 to 1.85 ; I ${ }^{2} 74 \%$. Additional file 3: Figure S1d), and the subgroup of studies in which remifentanil and sufentanil were compared (mean difference $-0.58 ; 95 \%$ CI -1.78 to 0.62 ; I ${ }^{2} 91 \%$. Additional file 3: Figure S1e).

\section{Assessment of publication biases}

Biases in the publication of the three outcome measures (duration of mechanical ventilation, time to extubation after cessation of sedation, and ICU-LOS) were evaluated using funnel plots. The funnel plots depicted in Fig. 4 were generally asymmetrical, which indicated the presence of publication bias. The points representing the evaluated studies in the three funnel plots were concentrated at the top showed that the studies had high precision and large sample sizes.

\section{Discussion}

The results of this meta-analysis suggested that the use of remifentanil was associated with a reduction in the duration of mechanical ventilation when compared with other opioids, findings that were supported by the results of subgroup of studies in which analgesia and sedation were administered and subgroup of studies in which remifentanil was compared with fentanyl; however, the subgroups of studies in which analgesia alone was administered and studies in which remifentanil was compared with morphine or sufentanil indicated the presence of no differences. Remifentanil was associated with reductions in time to extubation after sedation cessation and ICU-LOS but not reductions in hospital-LOS or costs.

The finding that remifentanil was found to reduce the duration of mechanical ventilation, time to extubation after sedation cessation, and ICU-LOS may be highly related to the unique pharmacokinetics and pharmacodynamics of remifentanil, namely, its rapid onset and offset, context-sensitive half-life that is hardly affected by the duration of infusion, and elimination that is independent of liver or renal function $[14,15]$. In the subgroups, the results of the studies comparing remifentanil with fentanyl showed a maximal mean difference of 3.85 hours. As a selective $\mu$-opioid receptor agonist $[16,17]$, remifentanil was similar to fentanyl in potency but different in pharmacokinetics. This result may indicate that remifentanil may be used as a substitute for fentanyl in some circumstances, especially in cases in which patients have developed kidney injuries or in which intermittent interruption of sedation and analgesia is needed to assess altered mental status. However, these results should be interpreted with caution for a few reasons. First, the mean differences between remifentanil and other opioids were only 1.5 hours for mechanical ventilation duration, 1 hour for time to extubation after sedation cessation, and 0.1 day for IC-LOS, which suggested that only miniscule differences may be identified in clinical practice. However, the potential benefits of remifentanil might be more apparent when used in patients with significant organ failure $[6,14]$, a 

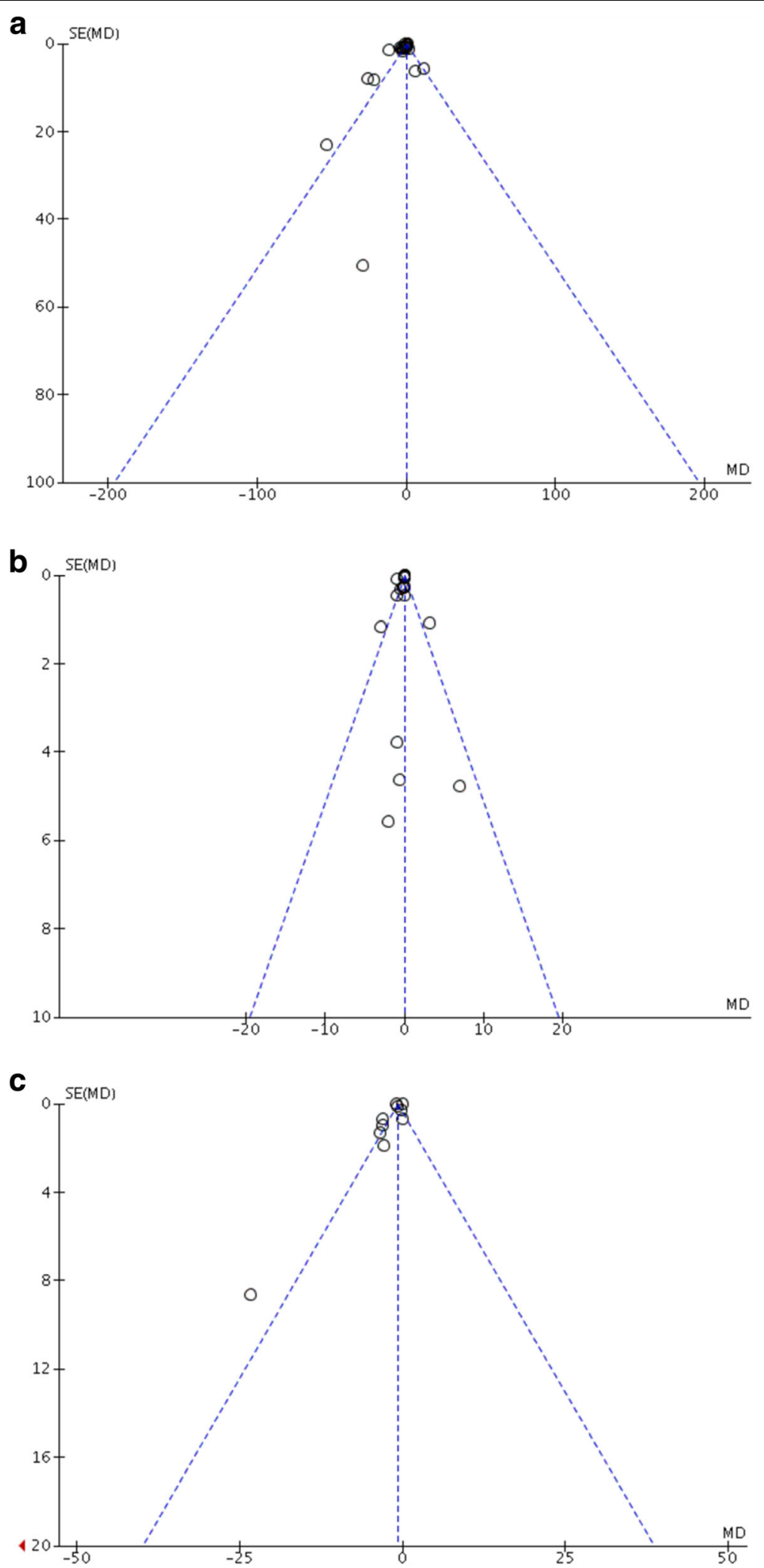

Fig. 4 Funnel plots. Funnel plots were generally asymmetrical. The hollow dots and dotted line indicate individual studies and 95\% confidence intervals, respectively. a Funnel plot of duration of mechanical ventilation. b Funnel plot of ICU-LOS. c Funnel plot of time to extubation after cessation of sedation 
hypothesis that more studies should explore. Moreover, neurologic assessment is essential for neurosurgical and neurotrauma patients; thus, the association between remifentanil and rapid and predictable awakening may be more meaningful in these patients, even though the difference between remifentanil and other opioids were less than 1 hour [5]. Second, high levels of heterogeneity were identified for all of the outcomes. There were remarkable differences across the included RCTs in terms of type of disease, analgesic agents and sedation protocols. We analysed the outcomes in subgroups classified by the use of different control groups and sedation protocols to reduce clinical heterogeneity; however, the statistical homogeneity was still obvious $\left(\mathrm{I}^{2}>70 \%\right.$, considered as high heterogeneity). In addition, we selected a random-effects model rather than fixed-effects model to address the observed heterogeneity. Third, the funnel plots suggested the presence of publication bias in the three evaluated outcomes, which may be because the pharmaceutical companies that manufactured remifentanil funded some of the included studies.

Remifentanil was not associated with a reduction of hospital-LOS, costs, mortality, of agitation, and no differences were observed in the subgroups of studies in which only analgesia was administered and subgroup of studies in which remifentanil was compared with morphine or sufentanil, which may be because remifentanil and other opioids are similar in most regards; however, these results should be interpreted with caution for a few reasons. First, these outcome measures were assessed in small samples, and high homogeneity was observed. The mortality rate was low and not statistically powered to assess certain clinical outcomes [18]. Second, the combination of sedatives and analgesics made the estimation of the effect of opioids more difficult. Moreover, the sedation protocols and agents differed from study to study. Third, hospital-LOS and costs may be mainly affected by the severity of diseases rather than the selection of analgesia agents. In addition, anaesthetic costs accounted for only a small fraction of the overall costs. Costs were highly variable, with 95\% CI ranging from -1590.98 to 171.55 dollars. Only four RCTs included assessments of costs $[11,12,19,20]$. The types of diseases that patients were affected by in the four studies varied considerably, and the mean Acute Physiology and Chronic Health Evaluation II (APACHE II) score varied from 20.1 to 46, suggesting the presence of large variations in cost. Further cost-effectiveness studies are needed to explore the association between analgesic agents and cost.

The strengths of our meta-analysis include the structured search strategy, retrieval of all identified studies and large sample size. Taking the measurement of mechanical ventilation duration as an example, we included
18 RCTs in the comparisons, while the previous metaanalysis only included four RCTs [9] and we believe that our results might be more convincing than the results of the previous meta-analysis due to the inclusion of a larger sample size of patients.

There are limitations to our meta-analysis. First, the choice of hypnotic differed widely from one study to another, and the analysis of the effects of hypnotic choice was, thus, more difficult to perform. Second, both clinical and statistical heterogeneities were high. In addition, most of the included RCTs (78\%) were of suboptimal quality. Third, we were unable to exclude publication bias, and negative studies may be missing, potentially resulting in overestimation of the effect sizes.

Taken together, remifentanil seems to be associated with reductions in the duration of mechanical ventilation, time to extubation after sedation cessation, and ICU-LOS. No significant differences were identified between remifentanil and other opioids in terms of hospital-LOS, costs, mortality or agitation.

\section{Conclusions}

Remifentanil seems to be associated with reductions in the duration of mechanical ventilation and time to extubation after sedation cessation. Additional studies are needed to further evaluate the efficacy and safety of remifentanil and the association between the use of remifentanil and cost in critically ill patients, especially patients undergoing long-term mechanical ventilation.

\section{Additional files}

Additional file 1: Appendix 1: PubMed search strategy. (PDF $18 \mathrm{~kb}$ )

Additional file 2: Figure S2. Secondary outcomes. There was no significant difference in hospital-LOS (a), costs (b), mortality (c) and agitation (d) in comparison with remifentanil and other opioids. (PDF $92 \mathrm{~kb}$ )

Additional file 3: Figure S1. Subgroup analyses. Remifentanil was associated with a reduction in duration of mechanical ventilation in subgroups of analgesia and sedation (b) and remifentanil comparing with fentanyl (c). There was no significant difference in subgroups of analgesia only (a), morphine (d), and sufentanil (e). (PDF 112 kb)

\begin{abstract}
Abbreviations
APACHE II: Acute Physiology and Chronic Health Evaluation II; Cl: Confidence interval; hospital-LOS: Length of stay in hospital; ICU: Intensive care unit; ICULOS: Length of stay in ICU; RA: Remifentanil acid; RCT: Randomized controlled trial; SAPS II: Simplified Acute Physiology Score II; WMD: Weighted mean difference
\end{abstract}

\section{Funding}

No external funding was required for this research.

Availability of data and materials

All data generated or analysed during this study are included in this published article.

Authors' contributions

YBZ and YHW searched the scientific literature and drafted the manuscript, collect the data and performed statistical analyses. XMX and BD contributed 
to conception, design, data interpretation, manuscript revision for critical intellectual content, and supervision of the study. All authors read and approved the manuscript.

\section{Ethics approval and consent to participate} Not applicable.

\section{Consent for publication}

Not applicable.

\section{Competing interests}

The authors declare that they have no competing interests.

\section{Publisher's Note}

Springer Nature remains neutral with regard to jurisdictional claims in published maps and institutional affiliations.

\section{Author details}

'Department of Critical Care Medicine, Fuxing Hospital, Capital Medical University, 20A FuXing Men Wai Da Jie, Xicheng District, Beijing 100038, China. ${ }^{2}$ Medical ICU, Peking Union Medical College Hospital, Peking Union Medical College and Chinese Academy of Medical Sciences, 1 Shuai Fu Yuan, Beijing 100730, China. ${ }^{3}$ Department of Critical Care Medicine, North China University of Science and Technology Affiliated Hospital, 73 Jianshe Road, Tangshan 063000, China

Received: 4 March 2017 Accepted: 5 July 2017

Published online: 03 August 2017

\section{References}

1. Dahaba AA, Grabner T, Rehak PH, List WF, Metzler H. Remifentanil versus morphine analgesia and sedation for mechanically ventilated critically ill patients: a randomized double blind study. Anesthesiology. 2004;101:640-6.

2. Carrasco G, Cabre L, Sobrepere G, Costa J, Molina R, Cruspinera A, Lacasa C. Synergistic sedation with propofol and midazolam in intensive care patients after coronary artery bypass grafting. Crit Care Med. 1998;2:844-51.

3. Soliman HM, Melot C, Vincent JL. Sedative and analgesic practice in the intensive care unit: the results of a European survey. Br J Anaesth. 2001;87:186-92

4. Payen JF, Chanques G, Mantz J, Hercule C, Auriant I, Leguillou JL, Binhas M, Genty C, Rolland C, Bosson JL. Current practices in sedation and analgesia for mechanically ventilated critically ill patients. Anesthesiology. 2007;106:687-95.

5. Wilhelm W, Kreuer S. The place for short-acting opioids: special emphasis on remifentanil. Crit Care. 2008:12 Suppl 3:S5. doi:10.1186/cc6152.

6. Breen D, Wilmer A, Bodenham A, Bach V, Bonde J, Kessler P, Albrecht S, Shaikh S. Offset of pharmacodynamic effects and safety of remifentanil in intensive care unit patients with various degrees of renal impairment. Crit Care. 2004:8:R21-30.

7. Cox EH, Langemeijer MWE, Gubbens-Stibbe JM, Muir KT, Danhof M. The comparative pharmacodynamics of remifentanil and its metabolite, GR90291 in a rat electroencephalographic model. Anesthesiology. 1999;90:535-44.

8. Westmoreland CL, Hoke JF, Sebel PS, Muir KT. Pharmacokinetics of remifentanil (Gl87084B) and its major metabolite (Gl90291) in patients undergoing elective inpatient surgery. Anesthesiology. 1993;79:893-903.

9. Tan JA, Ho KM. Use of remifentanil as a sedative agent in critically ill adult patients: a meta-analysis. Anaesthesia. 2009;64:1342-52.

10. Greco M, Landoni G, Biondi-Zoccai G. Remifentanil in cardiac surgery: a meta-analysis of randomized controlled trials. J Cardiothorac Vasc Anesth. 2012;26:110-6

11. Al MJ, Hakkaart L, Tan SS, Bakker J. Cost-consequence analysis of remifentanilbased analgo-sedation vs. conventional analgesia and sedation for patients on mechanical ventilation in the Netherlands. Crit Care. 2010;14:1-10.

12. Engoren $M$, Luther $G$, Fenn-Buderer N. A comparison of fentanyl, sufentanil, and remifentanil for fast-track cardiac anesthesia. Anesth Analg. 2001:93:859-64.

13. Spies C, Macguill M, Heymann A, Ganea C, Krahne D, Assman A, Kosiek HR, Scholtz K, Wernecke KD, Martin J. A prospective, randomized, double-blind, multicenter study comparing remifentanil with fentanyl in mechanically ventilated patients. Intensive Care Med. 2011:37:469-76.

14. Olivo SA, Macedo LG, Gadotti IC, Fuentes J, Stanton T, Magee DJ. Scales to assess the quality of randomized controlled trials: a systematic review. Phys Ther. 2008;88:156-75. doi:10.2522/ptj.20070147.
15. Steinlechner B, Dworschak M, Birkenberg B, Lang T, Schiferer A, Moritz A, Mora B, Rajek A. Low-dose remifentanil to suppress haemodynamic responses to noxious stimuli in cardiac surgery: a dose-finding study. $\mathrm{Br}$ J Anaesth. 2007:98:598-603.

16. Rozendaal FW, Spronk PE, Snellen FF, Schoen A, van Zanten AR, Foudraine NA, Mulder PG, Bakker J, UltiSAFE investigators, UltiSAFE investigators. Remifentanilpropofol analgo-sedation shortens duration of ventilation and length of ICU stay compared to a conventional regimen: a centre randomised, cross-over, open-label study in the Netherlands. Intensive Care Med. 2009;35:291-8.

17. James MK, Feldman PL, Schuster SV, Bilotta JM, Brackeen MF, Leighton HJ. Opioid receptor activity of Gl 87084B, a novel ultra-short acting analgesic, in isolated tissues. J Pharmacol Exp Ther. 1991;259:712-8.

18. Wong GT, Huang Z, Ji S, Irwin MG. Remifentanil reduces the release of biochemical markers of myocardial damage after coronary artery bypass surgery: a randomized trial. J Cardiothorac Vasc Anesth. 2010;24:790-6. doi: 10.1053/j.jvca.2009.09.012. Epub 2010 Jan 13.

19. Myles PS, Hunt JO, Fletcher H, Watts J, Bain D, Silvers A, Buckland MR. Remifentanil, fentanyl, and cardiac surgery: a double-blinded, randomized, controlled trial of costs and outcomes. Anesth Analg. 2002;95:805-12.

20. Liu K, Wang D, Ma Y. Remifentanil for analgesia and sedation in mechanically ventilated patients in intensive care unit. Zhonghua Wei Zhong Bing Ji Jiu Yi Xue. 2013;25:167-70.

21. Bhavsar R, Ryhammer PK, Greisen J, Rasmussen LA, Jakobsen CJ. Remifentanil compared with sufentanil does not enhance fast-track possibilities in cardiac surgery—a randomized study. J Cardiothorac Vasc Anesth. 2016;30:1212-20.

22. Muellejans B, Matthey T, Scholpp J, Schill M. Sedation in the intensive care unit with remifentanil / propofol versus midazolam/fentanyl: a randomised, open-label, pharmaco-economic trial. Crit Care. 2006;10:R91.

23. Muellejans B, Lopez A, Cross MH, Bonome C, Morrison L, Kirkham AJ. Remifentanil versus fentanyl for analgesia based sedation to provide patient comfort in the intensive care unit: a randomized, double-blind controlled trial. Crit Care. 2004:8:R1-11.

24. Karabinis A, Mandragos K, Stergiopoulos S, Komnos A, Soukup J, Speelberg B, Kirkham AJ. Safety and efficacy of analgesia-based sedation with remifentanil versus standard hypnotic-based regimens in intensive care unit patients with brain injuries: a randomised, controlled trial. Crit Care. 2004:8:R268-80.

25. Baillard C, Cohen Y, Toumelin PL, Karoubi P, Hoang P, Ait Kaci F, Cupa M, Fosse JP. Remifentanil-midazolam compared to sufentanil-midazolam for ICU long-term sedation. Ann Fr Anesth Reanim. 2005;24:480-6.

26. Breen D, Karabinis A, Malbrain M, Morais R, Albrecht S, Jarnvig IL, Parkinson $P$, Kirkham AJ. Decreased duration of mechanical ventilation when comparing analgesia-based sedation using remifentanil with standard hypnotic-based sedation for up to 10 days in intensive care unit patients: a randomised trial. Crit Care. 2005;9:R200-10.

27. Belhadj Amor M, Ouezini R, Lamine K, Barakette M, Labbène I, Ferjani M. Daily interruption of sedation in intensive care unit patients with renal impairment: remifentanil-midazolam compared to fentanyl-midazolam. Ann Fr Anesth Reanim. 2007;26:1041-4.

28. Carrer S, Bocchi A, Candini M, Donegà L, Tartari S. Short-term analgesia based sedation in the intensive care unit: morphine vs. remifentanil + morphine. Minerva Anestesiol. 2007:73:327-32.

29. Gerlach K, Uhlig T, Huppe M, Kraatz E, Saager L, Schmitz A, Dörges V, Schmucker P. Remifentanil-clonidine- propofol versus sufentanil-propofol anesthesia for coronary artery bypass surgery. J Cardiothorac Vasc Anesth. 2002;16:703-8.

30. Guggenberger H, Schroeder TH, Vonthein R, Dieterich HJ, Shernan SK, Eltzschig HK. Remifentanil or sufentanil for coronary surgery: comparison of postoperative respiratory impairment. Eur J Anaesthesiol. 2006;23:832-40.

31. Knapik M, Knapik P, Nadziakiewicz P, Misiołek H, Saucha W, Walaszczyk M, Dyaczyńska-Herman A. Comparison of remifentanil or fentanyl administration during isoflurane anesthesia for coronary artery bypass surgery. Med Sci Monit. 2006:12:PI33-8.

32. Maddali MM, Kurian E, Fahr J. Extubation time, hemodynamic stability, and postoperative pain control in patients undergoing coronary artery bypass surgery. An evaluation of fentanyl, remifentanil, and nonsteroidal antiinflammatory drugs with propofol for perioperative and postoperative management. J Clin Anesth. 2006;18:605-10.

33. Winterhalter M, Brandl K, Rahe-Meyer N, Osthaus A, Hecker H, Hagl C, Adams HA, Piepenbrock S. Endocrine stress response and inflammatory activation during $C A B G$ surgery. A randomized trial comparing remifentanil infusion to intermittent fentanyl. Eur J Anaesthesiol. 2008;25:326-35. 
34. Bedirli N, Boyaci A, Akin A, Esmaoglu A. Comparison of the effects of fentanyl and remifentanil on splanchnic tissue perfusion during cardiac surgery. J Anesth. 2007;21:94-8.

35. Chinachoti T, Kessler P, Kirkham A, Werawatganon T. Remifentanil vs morphine for patients in intensive care unit who need short-term mechanical ventilation. J Med Assoc Thai. 2002;85:S848-857.

36. Khanykin B, Siddiqi R, Jensen PF, Bigler DR, Atroshchenko GV. Comparison of remifentanil and low-dose fentanyl for fast-track cardiac anesthesia: a prospective randomized study. Heart Surg Forum. 2013;16:E324-328.

Submit your next manuscript to BioMed Central and we will help you at every step:

- We accept pre-submission inquiries

- Our selector tool helps you to find the most relevant journal

- We provide round the clock customer support

- Convenient online submission

- Thorough peer review

- Inclusion in PubMed and all major indexing services

- Maximum visibility for your research

Submit your manuscript at www.biomedcentral.com/submit
Biomed Central 